\title{
Experimental Research on the Performance of Polypropylene Fiber Foamed Ultra-lightweight Composites
}

\author{
Trong-Phuoc Huynh", ${ }^{1,}$ Van-Hien Pham', Tri-Khang Lam¹, Nguyen-Trong Ho ${ }^{2}$ \\ ${ }^{1}$ Department of Civil Engineering, College of Engineering Technology, Can Tho University, Vietnam \\ ${ }^{2}$ Faculty of Civil Engineering, VSB-Technical University of Ostrava, Czech Republic
}

Received June 12, 2020; Revised July 20, 2020; Accepted August 25, 2020

Copyright $@ 2020$ by authors, all rights reserved. Authors agree that this article remains permanently open access under the terms of the Creative Commons Attribution License 4.0 International License

\begin{abstract}
This experimental study was conducted to evaluate the effect of polypropylene (PP) fibers added into pre-foamed ultra-lightweight composites (PULC) with a target dry density of $600 \mathrm{~kg} / \mathrm{m}^{3}$. In this research, four PULC mixtures were designed with various PP fiber contents of $0,0.4,0.9,1.4 \%$ by total weight of binder while other ingredients, including cement, fly ash (FA), slag, water, and stone powder, were kept constant. The dosage of foam and superplasticizer was adjustable to achieve the same target dry density and workability of the PULC mixtures. The PULC samples were prepared in the laboratory. After casting, these samples were stored at the room temperature condition until the required ages to implement to test. Engineering properties of the PULC samples, including compressive strength, the dry density, the water absorption, the drying shrinkage, the thermal conductivity, and the microstructure analysis, were tested to evaluate the performance as well as the potential application of such materials in reality. The experimental results show that for the specimen of $0.9 \%$ PP fiber content, the fiber addition helped to improve and enhance its compressive strength reaching the value within the range of $2.5 \div 3.2 \mathrm{MPa}$. Furthermore, the thermal conductivity and the drying shrinkage decreased while the dry density gained a range of $639 \div 643 \mathrm{~kg} / \mathrm{m}^{3}$. This research further indicated that $0.9 \%$ of PP fiber content was the optimal dosage and it also demonstrated a significant influence of the application PP fiber into the production of PULC.
\end{abstract}

Keywords Pre-foamed Ultra-lightweight Composite, Dry Density, Polypropylene Fiber, Drying Shrinkage, Compressive Strength, Thermal Conductivity

\section{Introduction}

These days, the residential apartment building demand significantly increases due to the rapid development speed of globalization, especially in big cities. Consequently, the innovation of construction material needs to be paid more attention than before in order to achieve not only a technical satisfying but also cost-saving and eco-friendly. The application of foam concrete, particularly pre-foamed ultra-lightweight composite (PULC), has been developed to solve the above issues. The foam concrete eliminated coarse aggregates is to reduce a dead load of structures and it poses fire resistant, high sound, and thermal insulation features [1]. PULC becomes an effective material to decrease the self-weight of the whole structure due to the low-density range of $400 \div 1600 \mathrm{~kg} / \mathrm{m}^{3}$ in comparison with conventional concrete of about $2400 \mathrm{~kg} / \mathrm{m}^{3}$. Moreover, its thermal conductivity value is lower than conventional concrete, with the value in the range of $0.1 \div 0.7 \mathrm{~W} / \mathrm{mK}$ for concrete getting a dry density of $300 \div 1600 \mathrm{~kg} / \mathrm{m}^{3}$. Using a foaming agent makes the conductivity of heat being low caused by the presence of air voids in the matrix resisting the air passing [2]. Therefore, it makes PULC becomes an excellent thermal insulating composite.

So far, the mechanical characteristics of concrete have also been studied for several years. Adding polypropylene (PP) fibers into the reinforcement concrete could change its engineering properties. Particularly, adding PP into lightweight concrete leads to a reduction of workability [3, 4]. The slump flow of the pattern containing PP fibers with a low water-to-binder ratio of 0.37 was $76 \mathrm{~mm}$, compared to standard specimens and samples reinforced by steel fibers at $72 \mathrm{~mm}$ and $75 \mathrm{~mm}$, respectively [3]. Moreover, adding PP fibers with their density of $900 \div 910 \mathrm{~kg} / \mathrm{m}^{3}$ to lightweight concrete increased the concrete density $[4 \div 6]$. 
Hazlin et al. [6] previously stated that after using 0.05, 0.1, and $0.15 \%$ fiber content in foamed concrete, the density had a slight increase to $1.03,1.09$, and $7.38 \%$, respectively. Also, PP fibers can be used as a supplement material with a crucial role in changing the physical and mechanical properties of PULC. This paper described the impact of PP fibers on the physical, mechanical properties, and microstructure of PULC. The dry density, the water absorption, the thermal conductivity, and the drying shrinkage tests were proceeded to evaluate its properties. The mechanical performance of PULC was also determined by means of a compressive strength test. The microstructure of PULC reinforced with PP fibers would also be analyzed.

\section{Materials and Mixture Proportions}

\subsection{Materials Properties}

The raw materials used to produce PULC included water, foaming agent, PP fibers, cement, fly ash (FA), slag, stone powder, and superplasticizer (SP). It is noted that the cement, FA, slag, and stone powder used were locally available with a density of 3.09, 2.22, 2.84 , and $2.63 \mathrm{~g} / \mathrm{cm}^{3}$, respectively and Table 1 shows the chemical compositions of cement, FA, and slag. A foaming agent and SP were in liquid form that sourced from China with a density of 1.02 and $1.07 \mathrm{~g} / \mathrm{cm}^{3}$, respectively. To prepare the foam as shown in Figure 1(a), a foam generator was used with a foaming agent-to-water ratio of 0.025 .

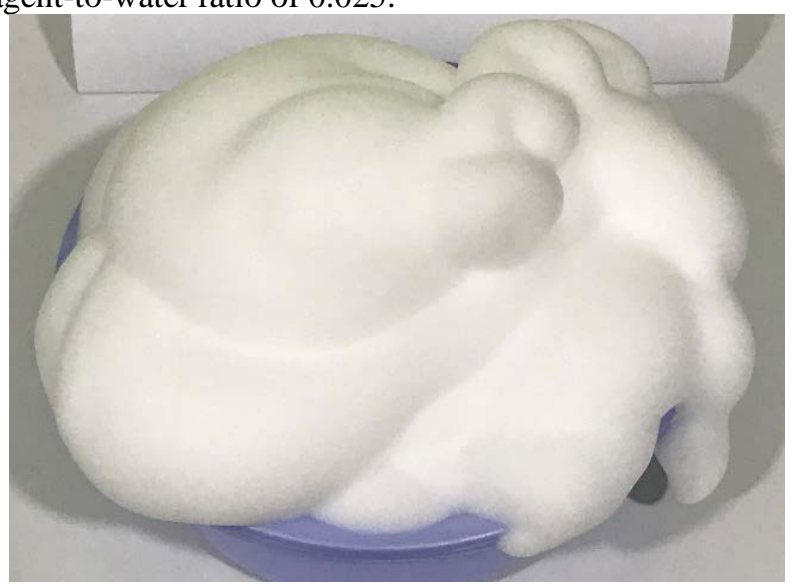

(a) Foam

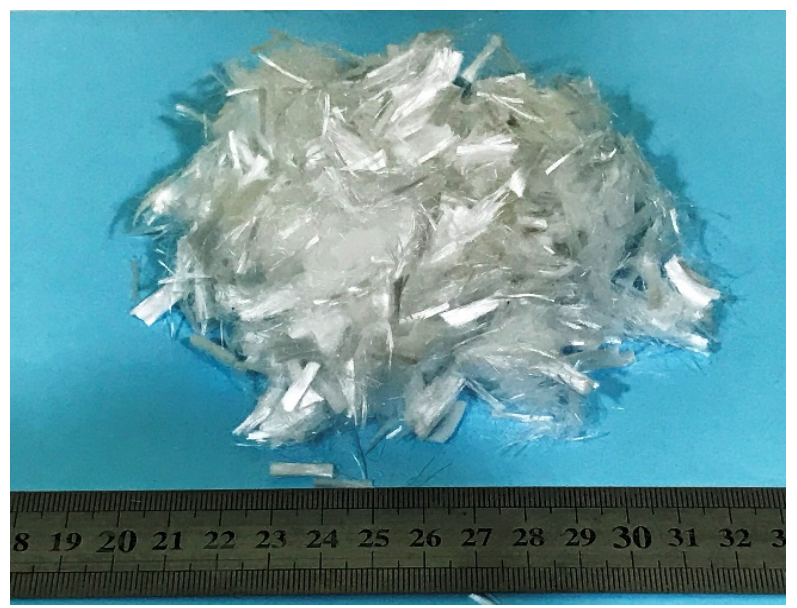

(b) PP Fiber

Figure 1. Foam and PP Fiber Used in This Study.

In addition, the density of PP fiber of $12 \mathrm{~mm}$ length was $0.91 \mathrm{~g} / \mathrm{cm}^{3}$ and the tensile strength of above $500 \mathrm{MPa}$ (Figure 1b) was added to the PULC mixtures to escalate the mechanical strength as well as improve the drying shrinkage performance. The scanning electron microscope (SEM) images and XRD patterns of the raw materials are shown in Figure 2. As shown, the shape of FA was mostly spherical with different sizes while the shape of both cement and slag was irregular. Furthermore, the particle size of FA was the largest whereas the particle size of slag was the smallest among the three materials. The aim of using slag in the PULC mixture was to reduce the amount of cement used in order to produce more environmentally friendly material. Figure 2(d) indicates that slag was more active under its amorphous phase as compared to FA and cement [7].

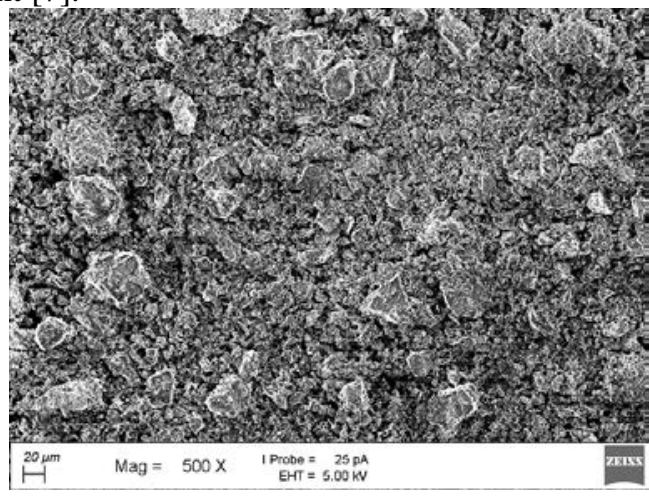

(a) Cement 


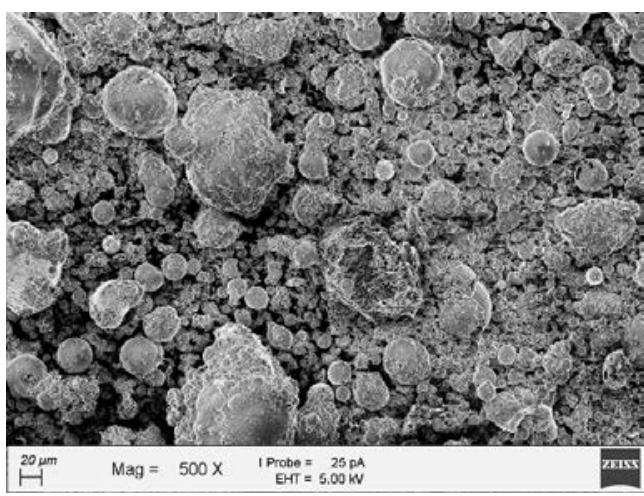

(b) FA

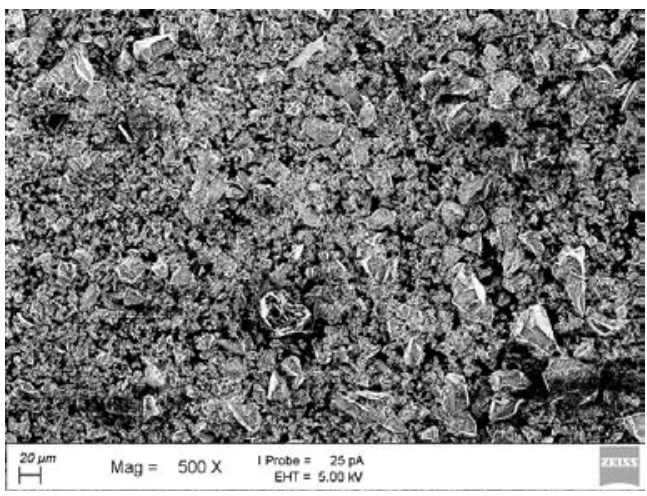

(c) Slag

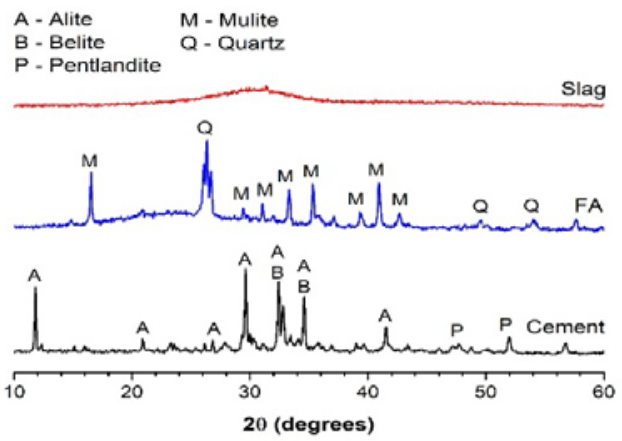

(d) XRD Patterns

Figure 2. SEM Images and XRD Patterns of Raw Materials.

\subsection{Mixture Design and Proportions}

To concentrate on the evaluation of the influence of the presence of PP fiber on the engineering properties, PP fiber was added into the mix at $0.4,0.9$, and $1.4 \%$ by mass of total binder (including cement, FA, and slag). As reported by Sathish et al. [1], 20\% replacement of slag for cement performed the highest compressive strength. In this study, therefore, $20 \%$ of cement was replaced by slag for all PULC mixtures and PP fibers would be added into these mixtures with the above-mentioned quantity to evaluate its influence on the engineering properties of the PULC samples. A respective water-to-binder (w/b) ratio, stone powder- to-binder ratio, and FA-to-binder ratio of 0.35 , 0.35 , and 0.1 were applied for all PULC mixtures. The amount of foam and SP was adjustable to get the target dry density of about $600 \mathrm{~kg} / \mathrm{m}^{3}$ and a flowable-uniform mixture. The mix proportions of PULC mixtures are given in Table 2.

\section{Samples Preparation and Test Methods}

\subsection{Mixing Procedures and Samples Preparation}

All dry materials consisting of cement, slag, FA, and stone powder were firstly mixed in a mixer in accordance with ASTM C305 [8] for a minute before adding water to prevent local distribution and let materials distribute uniformly. The stage of slowly adding one-third of water into the batch and mixing for one minute was repeated twice. Afterward, PP fibers and SP were added in order to maintain the flowability of the fresh mixture. After adding SP, stop the mixer and scrape down into the batch any paste that sticks on sides of the mixing bowl. Foam, which was created by a foam generator prior to mixing, was then added into the batch, and mixing in two minutes to obtain a homogeneous mixture. The fresh mixture was poured into molds with different sizes for various tests. All the samples were de-molded after 24 hours and they were also cured at room temperature condition until the time for testing.

\subsection{Test Methods}

The detail of test programs to evaluate the engineering properties and microstructure of the PULC samples is summarized in Table 3.

Table 1. Chemical Compositions of Raw Materials.

\begin{tabular}{|c|c|c|c|c|c|c|}
\hline Cementitious Materials & $\mathrm{SiO}_{2}$ & $\mathrm{Al}_{2} \mathrm{O}_{3}$ & $\mathrm{Fe}_{2} \mathrm{O}_{3}$ & $\mathrm{MgO}$ & $\mathrm{CaO}$ & Others \\
\hline Cement & 23.49 & 6.01 & 3.65 & 1.98 & 59.89 & 4.98 \\
\hline FA & 59.17 & 26.71 & 6.06 & 0.89 & 1.07 & 6.10 \\
\hline Slag & 35.88 & 12.99 & 0.32 & 7.99 & 38.13 & 4.69 \\
\hline
\end{tabular}


Table 2. Mixture Proportions of the PULC Specimens.

\begin{tabular}{|c|c|c|c|c|c|c|c|c|}
\hline \multirow{2}{*}{ PULC Mix } & \multicolumn{9}{|c|}{ Ingredient proportions (unit: gram ) } \\
\cline { 2 - 11 } & Cement & FA & Slag & Foam & Water & SP & Stone Powder & Fiber \\
\hline S20F00 & 1400 & 200 & 400 & 107 & 700 & 4.7 & 700 & 0 \\
\hline S20F04 & 1400 & 200 & 400 & 107 & 700 & 4.7 & 700 & 8 \\
\hline S20F09 & 1400 & 200 & 400 & 113 & 700 & 4.7 & 700 & 18 \\
\hline S20F14 & 1400 & 200 & 400 & 120 & 700 & 4.7 & 700 & 28 \\
\hline
\end{tabular}

Table 3. Details of Test Programs for Evaluating the Performance of PULC samples.

\begin{tabular}{|c|c|c|c|}
\hline Test name & Test age (days) & Samples size (mm) & Reference standard \\
\hline Compressive strength & $3,7,14,28$ & $50 \times 50 \times 50$ & ASTM C109 [9] \\
\hline Drying shrinkage & $1,3,7,14,28 \times 25 \times 285$ & ASTM C596 [10] \\
\hline Dry density & 28 & $50 \times 50 \times 50$ & ASTM C567 [11] \\
\hline Water absorption & 28 & $50 \times 50 \times 50$ & USTM C1585 [12] \\
\hline Thermal conductivity & 28 & $\begin{array}{c}\text { Using a broken piece from the device model } \\
\text { ISOMET 2114 }\end{array}$ & $\begin{array}{c}\text { Using scanning electron } \\
\text { microscope of ZEISS [13] }\end{array}$ \\
\hline SEM observation & &
\end{tabular}

\section{Results and Discussion}

\subsection{Compressive Strength}

The compressive strength is one of the most key mechanical properties of foam concrete, which is the main parameter used in quality control. Figure 3 demonstrated the strength development of PULC with various PP fiber contents. An overview of the figure revealed that while PULC samples containing $0.4 \div 0.9 \%$ of PP fiber witnessed an upward trend, the reverse trend was also true for the compressive strength of the samples incorporating higher than $0.9 \%$ of PP fiber. However, samples reinforced by adding PP fiber had higher values of the compressive strength than that of the non-fiber PULC samples.

As shown in Figure 3, after 28-day age, the PULC samples with $0.4,0.9$, and $1.4 \%$ fiber addition registered compressive strength values of $2.7,3.1$, and $2.8 \mathrm{MPa}$, respectively. On average, these compressive strengths values being about $8.1,26.3$, and $33.6 \%$ were higher than that of the free-fiber PULC samples. Thus, it is clear that the compressive strength of the PULC samples increased when PP fiber was added to the mixture at the content of less than $1 \%$. However, further adding PP fiber of higher than $1 \%$ caused the reduction in the PULC's strength. The leading cause of the compressive strength reduction of samples containing higher than $1 \%$ of PP fiber may be the presence of a high amount of PP fiber interferes with the cohesiveness of the matrix and it leads to less compactness and increased porosity (as observed by SEM observation presented in Figure 8), which reduced the compressive strength [14]. However, the enhanced compressive strength of the PULC samples was observed at the optimal amount of added PP fiber [15]. In this case, the compressive strength of all specimens was increased, which could be attributed to generating a good cohesion between fibers and other constituents [16].

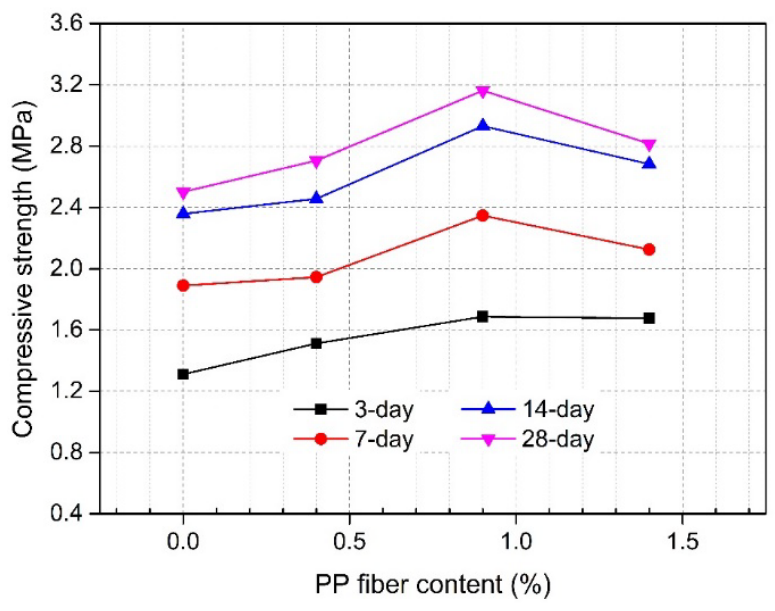

Figure 3. Compressive Strength of PULC Samples.

\subsection{Dry Density and Water Absorption}

The dry density could be used to evaluate the lightweight property of PULC. As shown in Figure 4, the inclusion of PP fiber might reduce PULC's weight because of the relatively low density of the fiber as aforementioned. Dry densities of PULC samples with $0,0.4,0.9$, and $1.4 \%$ of PP fiber were $642,639,643$, and $641 \mathrm{~kg} / \mathrm{m}^{3}$, respectively. Hence, all of the PULC samples using in this study satisfied the standard requirement in terms of the designed dry density as stipulated by the TCVN 9029:2017 standard [17]. With adding PP fiber, the dosage of foam was adjustable in order to obtain the target dry density of $600 \mathrm{~kg} / \mathrm{m}^{3}$ for all PULC mixtures. It can be seen that the dry density of the 
PULC sample incorporating $0.9 \%$ of PP fiber was highest among the samples. This may be caused by the non-uniform distribution of PP fibers within the sample matrix.

Another key characteristic of PULC was water absorption that was indicated in Figure 5. The figure shows that water absorption of the PULC samples increased with fiber content. In fact, the samples with $0.4,0.9$, and $1.4 \%$ fiber contents absorbed 48.1, 50.4, and 50.9\% amount of water, which was higher than the water absorption rate of the control sample (46.1\%). Once again, it could be said that water absorption increased proportionally to fiber contents. As above mentioned, this may be due to the increase in the number of voids when adding more PP fiber (Figure 8). It is assumed that PP fiber also absorbed water on its surface. Higher PP fiber contents resulted in an increased surface area, which consequently increases the water demand of the mixture. Then, water was evaporated during the drying period and introduced many pores, consequently resulted in a higher water absorption level.

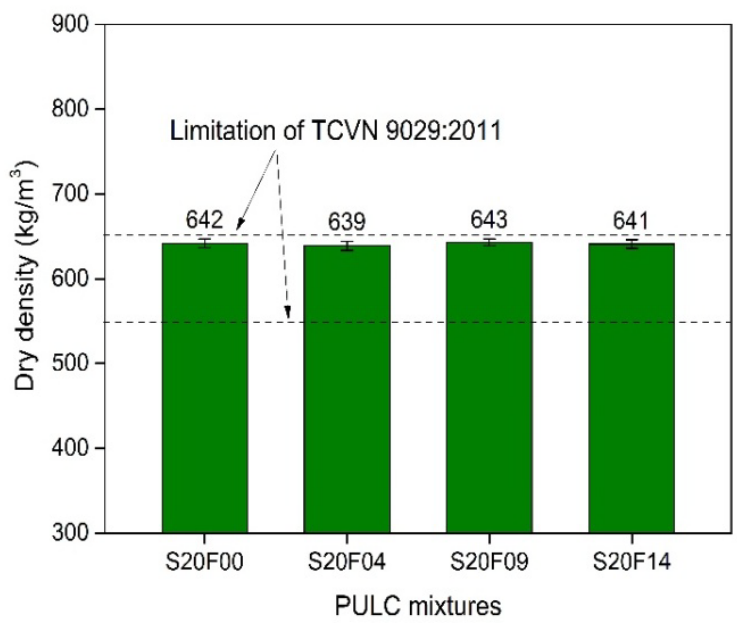

Figure 4. Dry Density of PULC Samples.

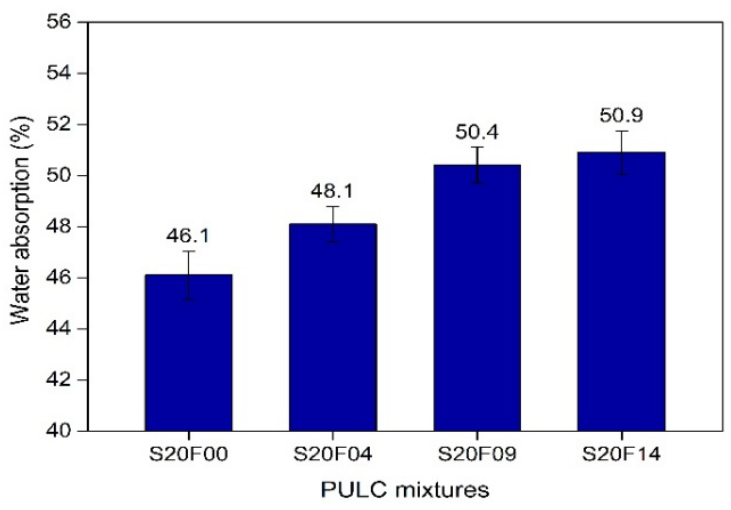

Figure 5. Water Absorption of PULC Samples.

\subsection{Drying Shrinkage}

The drying shrinkage of PULC samples is demonstrated in Figure 6. There was an opposite proportion between PP fiber contents and the percentage of length change of the PULC specimens. It could be observed that the drying shrinkage of the PULC samples reduced with the addition of PP fiber and the more the PP fiber added, the lower the drying shrinkage was. As presented in Figure 6, the change in length of the 28-day-old PULC samples with various fiber contents of $0,0.4,0.9$, and $1.4 \%$ were -0.0561 , $-0.0514,-0.0489$, and $-0.0479 \%$, respectively. It is found that both ends of PP fibers had a special shape in which the mechanical anchorage was strengthened and the interaction between fiber and matrix was increased. This mechanism was the main reason to lead a reduction of the dry shrinkage in mixture reinforced with PP fiber [16], [18]. Moreover, some previous studies also stated that the presence of PP fiber not only restrained the shrinkage but also reduced the crack propagation within the material's structure [19], [20].

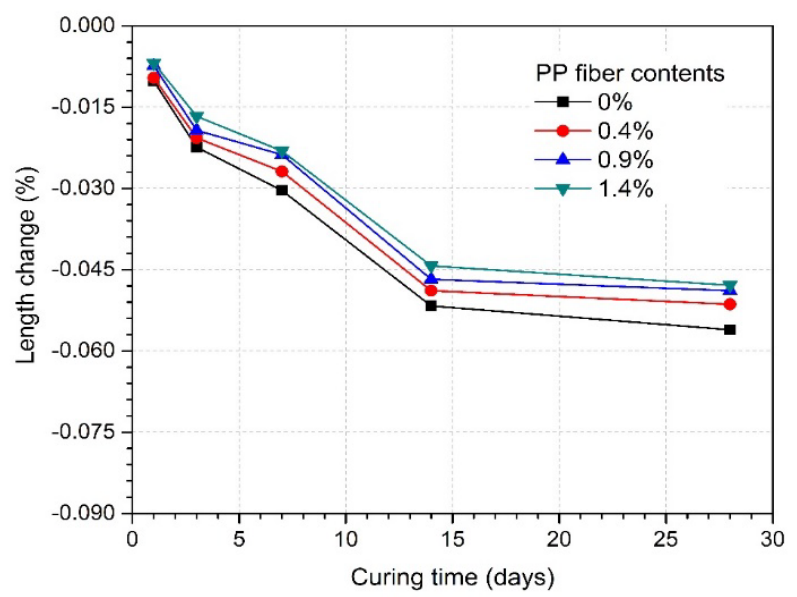

Figure 6. Drying Shrinkage of PULC Samples.

\subsection{Thermal Conductivity}

The test results for the thermal conductivity of all PULC samples are illustrated in Figure 7. Regarding the thermal conductivity, there were inhomogeneous changes among specimens with different PP fiber contents. The sample with $0.4 \%$ of PP fiber content registered a thermal conductivity value of $0.129 \mathrm{~W} / \mathrm{mK}$, which was lower than that of the samples with $0 \%$ and $0.9 \%$ fiber contents $(0.134$ and $0.136 \mathrm{~W} / \mathrm{mK}$, respectively). After adding more fiber content into the third pattern, the sample with $1.4 \%$ fiber content slightly decreased to $0.131 \mathrm{~W} / \mathrm{mK}$. The unusual changes could be ascribed to the non-uniform distribution of PP fiber in the figure for $0.9 \%$ fiber content. For other samples reinforced by PP fiber, fibers were distributed more uniform, it made more pores in these specimens after drying because PP fiber was a hydrophobic material and retained water [2], [21]. As the above discussion, during the hardening process, there are more empty air voids due to the retained water being dried out. As a result, the transfer of heat through the PULC samples was lower, which result in obtaining lower thermal conductivity [2]. Low thermal conductivity makes PULC samples more advantageous 
compared to other normal materials.

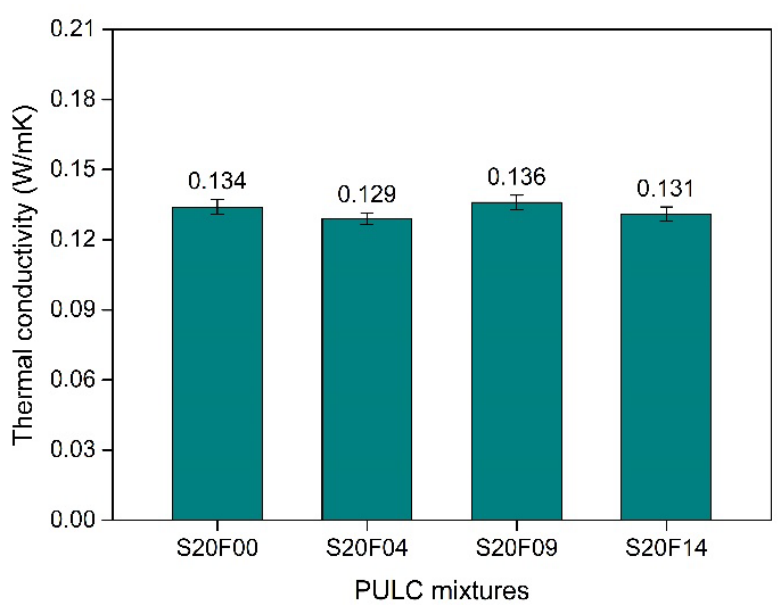

Figure 7. Thermal Conductivity of PULC Samples.

\subsection{Microstructure Analysis}

The analyzing microstructure results of samples by SEM were demonstrated in Figure 8. There was a gradual increase in porosity inside the specimens. As shown on figures, the fiber content was greater and the porosity was more. In fact, the size of the air voids/ pores of PULC samples with higher PP fiber contents were bigger than the samples with less fiber. The main reason was that the fiber made its surrounding composite denser due to the fibrillated process and interfacial adhesion. The network of fibers created bubbles, which produced microporous and decreased interfacial bonding in the matrix [6]. In this case, PP fiber contributed to bridging force crossing the cracks formed within the matrix and reduced the cracks. This phenomenon could be conducive to an increase in water absorption and decrease the dry density, the thermal conductivity, and the drying shrinkage of the PULC samples as previously discussed. Moreover, good interfacial adhesion between the PP fibers and the composite material was observed at $0.9 \%$ of fiber content (Figure 8c), which registered the highest compressive strength among the tested samples.

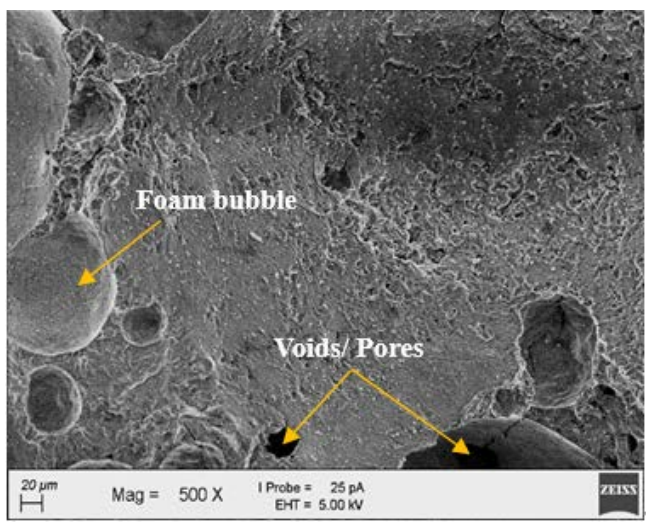

(a) S20F00

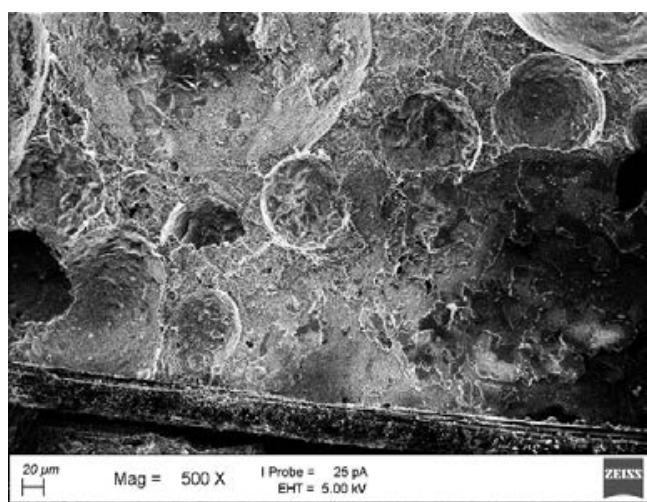

(b) $\mathrm{S} 20 \mathrm{F04}$

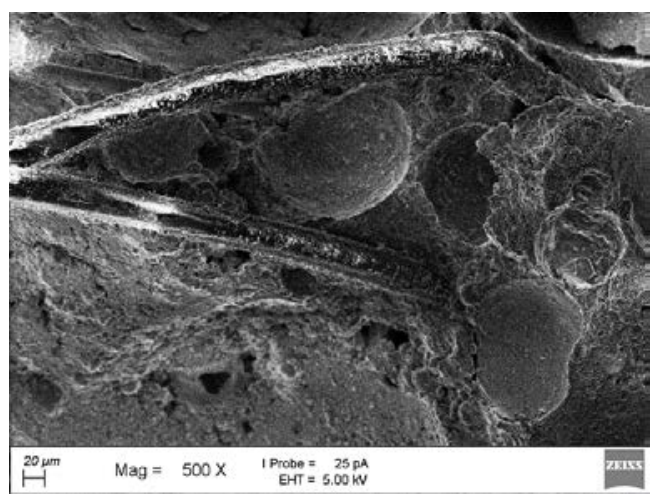

(c) S20F09

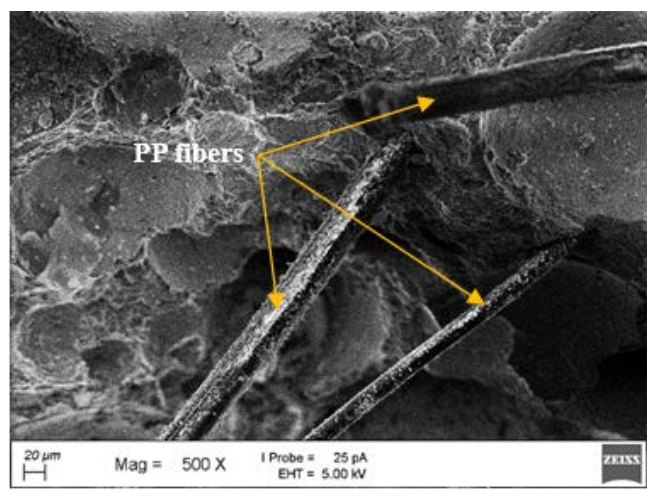

(d) $\mathrm{S} 20 \mathrm{~F} 14$

Figure 8. SEM Morphologies of PULC Samples.

\section{Conclusions}

This paper examined the effect of PP fibers at various contents on the physical and mechanical properties of PULC. In accordance with experimental results, the following vital conclusions can be drawn:

Firstly, PP fibers could be introduced to increase the compressive strength of the PULC samples, and the optimal dosage of fiber was $0.9 \%$. It could boost strength up to $26.3 \%$, at $3.2 \mathrm{MPa}$, compared to the strength of fiber-free PULC samples (2.5 MPa).

Secondly, the addition of PP fiber was found to reduce the dry density of the PULC samples compared to that of 
the control samples $\left(642 \mathrm{~kg} / \mathrm{m}^{3}\right)$, except the sample with $0.9 \%$ fiber content $\left(643 \mathrm{~kg} / \mathrm{m}^{3}\right)$. Therefore, PP fibers might be used to both improve strength and decrease the self-weight of the PULC.

Thirdly, the water absorption of the fiber-free PULC sample was $46.1 \%$. It was lower than that of the samples reinforced by PP fibers (48.1, 50.4, and 50.9\%). While the figures for water absorption witnessed an upward trend after adding more PP fiber, the reverse was true for the figure of drying shrinkage. There was a slow drop from -0.0561 down $-0.0479 \%$ in drying shrinkage. None PP fiber was the specimen that shrunk most because the link between aggregate and binder was not as sustainable as the link between fibers and other aggregates.

\section{Acknowledgments}

The authors would like to thanks Huynh's research group at Can Tho University, Vietnam for their assistance during the experimental works.

\section{REFERENCES}

[1] P. Sathish, C. Neeladharan, K. Ilakkiya, N. Jeevitha, R. Mageshwari, P. Nivetha. Behaviour of lightweight foam concrete block by using GGBS and foaming agent, International Journal of Advanced Research Trends in Engineering and Technology, Vol. 5, No. 5, 109-111, 2018. https://doi.org/10.20247/IJARTET.2018.05S05030021

[2] A.A. Jhatial, W.I. Goh, N. Mohamad, U.J. Alengaram, K.H Mo. Effect of polypropylene fibres on the thermal conductivity of lightweight foamed concrete, MATEC Web of Conferences, Vol. 150, 03008, 2018. https://doi.org/10.1051/matecconf/201815003008

[3] R. Madandoust, M. Kazemi, P.K. Talebi, J.D. Brito. Effect of the curing type on the mechanical properties of lightweight concrete with polypropylene and steel fibres, Construction and Building Materials, Vol. 223, 1038-1052, 2019.

https://doi.org/10.1016/j.conbuildmat.2019.08.006

[4] X. Liu, T. Wu, X. Yang, H. Wei. Properties of self-compacting lightweight concrete reinforced with steel and polypropylene fibers, Construction and Building Materials, Vol. 226, 388-398, 2019.

https://doi.org/10.1016/j.conbuildmat.2019.07.306

[5] N.A. Libre, M. Shekarchi, M. Mahoutian, P. Soroushian. Mechanical properties of hybrid fiber reinforced lightweight aggregate concrete made with natural pumice, Construction and Building Materials, Vol. 25, 2458-2464, 2011. https://doi.org/10.1016/j.conbuildmat.2010.11.058

[6] A.R. Hazlin, A. Iman, N. Mohamad, W.I. Goh, L.M. Sia, A. A.A. Samad, N. Ali. Microstructure and tensile strength of foamed concrete with added polypropylene fibers, MATEC Web of Conferences, Vol. 103, 01013, 2017. https://doi.org/10.1051/matecconf/201710301013
[7] C.T. Chen, H.A. Nguyen, T.P. Chang, T.R. Yang, T.D. Nguyen. Performance and microstructural examination on composition of hardened paste with no-cement SFC binder, Construction and Building Materials, Vol. 76, 264-272, 2015.

http://dx.doi.org/10.1016/j.conbuildmat.2014.11.032

[8] ASTM C305. Standard practice for mechanical mixing of hydraulic cement pastes and mortars of plastic consistency, ASTM International, West Conshohocken, PA, 2014. https://www.astm.org/Standards/C305

[9] ASTM C109. Standard test method for compressive strength of hydraulic cement mortars, ASTM International, West Conshohocken, PA, 2020.

https://www.astm.org/Standards/C109

[10] ASTM C596. Standard test method for drying shrinkage of mortar containing hydraulic cement, ASTM International, West Conshohocken, PA, 2018. https://www.astm.org/Standards/C596

[11] ASTM C567. Standard test method for determining density of structural lightweight concrete, ASTM International, West Conshohocken, PA, 2019.

https://www.astm.org/Standards/C567.htm

[12] ASTM C1585. Standard test method for measurement of rate of absorption of water by hydraulic cement concretes", ASTM International, West Conshohocken, PA, 2013. https://www.astm.org/Standards/C1585

[13] C. Liu, J. Luo, Q. Li, S. Gao, Z. Jin, S. Li, P. Zhang, S. Chen. Water-resistance properties of high-belite sulphoaluminate cement-based ultra-light foamed concrete treated with different water repellents, Construction and Building Materials, Vol. 228, 1-17, 2019.

https://doi.org/10.1016/j.conbuildmat.2019.116798

[14] A.H. Hasan, N.R. Maroof, Y.A. Ibrahim. Effect of polypropylene fiber content on strength and workability properties of concrete, Polytechnic Journal, Vol. 29, No. 1, 7-12, 2019.

https://doi.org/10.25156/ptj.v9n1y2019.pp7-12

[15] M. Mastali, A. Dalvand. Fresh and hardened properties of self-compacting concrete reinforced with hybrid recycled steel-polypropylene fiber, Journal of Materials in Civil Engineering, Vol. 29, No. 6, 0001851, 2017. https://doi.org/10.1061/(ASCE)MT.1943-5533.0001851

[16] R. Bagherzadeh, H.R. Pakravan, A.H. Sadeghi, M. Latifi, A.A. Merati. An investigation on addding polypropylene fibers to reinforce lightweight cement composites, Journal of Engineered Fibers and Fabrics, Vol. 7, No. 4, 13-21, 2012. https://doi.org/10.1177/155892501200700410

[17] TCVN 9029:2017. Lightweight concrete - Foam concrete and non-autoclaved aerated concrete products - Specifications, Vietnamese Standard, 2017 (in Vietnamese). https://vanbanphapluat.co/tcvn-9029-2011-be-tong-nhe-gac h-be-tong-bot-khi-khong-chung-ap

[18] Z. Abdollahnejad, Z. Zhang, H. Wang, M. Mastali. Comparative study on the drying shrinkage and mechanical properties of geopolymer foam concrete incorporating different dosages of fiber, sand and foam agents, In: D. Hordijk and M. Luković (Eds) High Tech Concrete: Where Technology and Engineering Meet. Springer, Cham, pp. 42-48, 2018. 
https://doi.org/10.1007/978-3-319-59471-2_6

[19] G.M.S. Islam, S.D. Gupta. Evaluating plastic shrinkage and permeability of polypropylene fiber reinforced concrete, International Journal of Sustainable Built Environment, Vol. 5, No. 2, 345-354, 2016.

https://doi.org/10.1016/j.ijsbe.2016.05.007

[20] T. Aly, J.G. Sanjayan, F. Collins. Effect of polypropylene fibers on shrinkage and cracking of concretes, Materials and
Structures, Vol. 41, 1741-1753, 2008.

https://doi.org/10.1617/s11527-008-9361-2

[21] A.A. Jhatial, W.I. God, N. Mohamad, T.A. Rind, A.R. Sandhu. Development of thermal insulating lightweight foamed concrete reinforced with polypropylene fibers, Arabian Journal for Science and Engineering, Vol. 45, 4067-4076, 2020.

https://doi.org/10.1007/s13369-020-04382-0 